Invest. pens. crit.

Vol. 2, No. 3, enero-abril 2014.

pp. $53-58$

\title{
El impacto neuropsicológico de las tecnologías de la información
}

\section{Eduardo Espino ${ }^{1, *}$}

1Profesor, Escuela de Psicología, Universidad Santa María La Antigua, Panamá.

*Autor para correspondencia. Email: eduardoabel.espino@gmail.com

Recibido: 12 de febrero de 2014

Aceptado: 15 de abril de 2014

La computadora y los teléfonos celulares móviles junto a otros artefactos tecnológicos han pasado a formar parte imprescindible de nuestra vida cotidiana. La profundización de este fenómeno de "informatización" de la vida social, de la cultura y de la vida diaria de millones de personas ha creado un ambiente complejo cuyas ramificaciones y consecuencias apenas estamos empezando a calibrar. El niño y adolescente de hoy nace en un entorno muy distinto al de hace 25 años cuando en 1989 podemos ubicar el inicio de la era de la globalización o mundialización luego de la caída de los regímenes totalitarios; comenzando así un proceso de interconexión y de intercambio intenso de ideas, personas, bienes comerciales y culturales. La niñez como etapa en la que comienza la socialización de todo ser humano, es cualitativamente distinta a la de antes de la era de la computarización. El niño y adolescente de hoy viven en una sociedad muy cambiante en la que lo único seguro es el cambio y el aceleramiento del ritmo de vida.

Lo anterior es resultado de que una "hiperconexión y la tendencia creciente de llenar cada segundo de la vida con alguna actividad electrónica está generando nuevos fenómenos de comportamiento". Nace la era y la generación de la interconexión.

Podemos segmentar o dividir los efectos psicológicos-psiquiátricos de la informatización de la cultura, la sociedad y de los hábitos de vida de la siguiente manera:

\section{1-Neurocognitivos}

La computarización de muchas tareas cotidianas, sobre todo las relacionadas a la búsqueda, asimilación y evocación de datos y de información en general así como su construcción y reconstrucción interna ha llevado a una creciente disminución de la memoria personal. Desde la tradición oral, pasando por la lectura de textos impresos hasta la abundancia de datos que ingresan a los artefactos electrónicos, el hombre se ha acostumbrado a depender menos del almacenamiento a largo plazo de información. Cada vez se necesita menos la memoria porque 
Invest. pens. crit.

Vol. 2, No. 3, enero-abril 2014.

pp. $53-58$

todo se puede consultar. Cuando no existían los libros modernos, antes del siglo XIV, todo debía ser memorizado a largo plazo para mantener vivo el flujo de tradiciones y experiencias pasadas. Desde los libros impresos hasta las computadoras de hoy el ser humano es sometido a un bombardeo infinito de datos, caudal de hechos, opiniones, ideas y narraciones que jamás había tenido a su alcance.

Dice Nicholas Carr (2010), ensayista y observador de la sociedad informática, que

La llegada de la internet y sus bancos de datos, ilimitados y fáciles de consultar, trajo un nuevo cambio, no sólo en la manera de ver la memorización, sino de ver la memoria misma. La red rápidamente llegó a verse como un sustituto, más que un suplemento, de la memoria personal.

Clive Thompson, redactor de "Wired", una revista sobre tecnologías electrónicas, citado por Carr (2010) en su libro Superficiales: ¿Qué está Haciendo Internet con Nuestras Mentes?, dice que "casi he dejado de esforzarme en recordar cualquier cosa porque cualquier información se puede recabar 'on-line' al instante". Esto último tiene sus repercusiones en el rendimiento escolar de jóvenes estudiantes que muestran apatía en el análisis y memorización de textos académicos; acostumbrados a tempranas edades a sentirse apáticos a retener datos porque "todo está en internet". Se sienten empoderados en sus artefactos conectados a la web que al estar ansiosos por revisarlos a cada momento, se distraen con facilidad; lo que puede incidir en la baja del rendimiento intelectual y en la ejecución de tareas escolares o universitarias. Existen "servidores cognitivos" externos que moldean los procesos mentales y cerebrales que afectan la memoria a corto y largo plazo por efecto de una especie de "adormecimiento neurocognitivo" del cerebro cuya plasticidad sináptica es alterada.

Los psicólogos, psiquiatras y neurólogos saben que existen más de un tipo de memorias. Neurocognitivamente esto se traduce en que la memoria a corto plazo no se convierte en memoria de largo plazo inmediatamente sino luego de una hora o más cuando se empiezan a consolidar. Las distracciones frecuentes de los artefactos informáticos pueden barrer los recuerdos nacientes en la mente.

Científicos de la Universidad de Pennsylvania demostraron en los años 60 del siglo pasado que la memoria a corto y largo plazo son dos procesos biológicos diferentes. Kandel, en los años 90, en sus experimentos con el molusco Aplysia demostró que las conexiones neuronales intervienen en la consolidación de las memorias en la medida en que una experiencia mientras más se repita más duradero será un recuerdo. La memoria a corto plazo produce un cambio en la función de las sinapsis y las de largo plazo requieren cambios anatómicos intraneuronales. Las interneuronas producen más neurotransmisor serotonina afinando las conexiones nerviosas de los circuitos de la memoria mediante síntesis proteica y activación de glutamato que está invo- 
Invest. pens. crit.

Vol. 2, No. 3, enero-abril 2014.

pp. $53-58$

lucrado en la formación de huellas mnésicas cerebrales al aumentar la actividad eléctrica neuronal. Entonces, gracias a la neuroplasticidad cerebral, nuestras experiencias conforman continuamente nuestro comportamiento y al estar expuesto un niño o adolescente al tipo de actividad interactiva sin almacenamiento de información estando varias horas y meses frente a los aparatos informáticos es de esperarse un efecto a corto y mediano plazo sobre su programación cerebral y cognitiva que lo predispone a patrones de conducta orientados a la no memorización y dependencia de los artefactos tecnológicos para la mínima experiencia intelectual. La calidad de los recuerdos depende de cómo se procese la información y al menoscabarse la memoria biológica se induce la "externalización de la memoria” perdiéndose su riqueza. Cuando se evoca un recuerdo se reinicia la consolidación por lo que cuando se devuelve a la memoria de trabajo una memoria explícita; a largo plazo se convierte en una nueva memoria a corto plazo que al reconsolidarse produce más reconexiones. La web impone presiones a la memoria de trabajo desviando recursos en la capacidad de razonamiento y obstruyendo la consolidación de las memorias a largo plazo. Dice Nicholas Carr (2010) que la calculadora es una herramienta que ayuda a la memoria mientras la web es una "tecnología del olvido".

La neuropsicología nos ilustra cómo la atención consciente comienza en los lóbulos frontales de la corteza cerebral imponiendo un control ejecutivo sobre el cerebro medio facilitando la liberación de dopamina a nivel del hipocampo; desde donde inicia la consolidación de la memoria explícita activando genes que promueven síntesis de proteínas. Si el flujo de mensajes en mutua competencia que recibe nuestro cerebro al usar internet es muy alto, se sobrecarga la memoria de trabajo y hace más difícil que los lóbulos frontales enfoquen la atención perturbando el mecanismo de consolidación de memorias; la plasticidad neuronal hace que el uso continuo de internet "entrene" a nuestro cerebro para distraerse y procesar la información y datos eficientemente por su rapidez pero sin atención sostenida. A mediano plazo el intelecto se externaliza a la máquina y también la identidad de la persona. El psicólogo Williams James acotaba que "la conexión es el yo" en el año 1892.

El ser humano de la era del conocimiento y la información está sujeto a un proceso de alienación o enajenación: está en muchos casos "hiperinformado superficialmente y paralizado cognitivamente". La baja en su capacidad para enfocar su atención al sumergirse en un constante mundo de rápido flujo de datos y comunicaciones lo convierte en un ser más pasivo e indiferente.

\section{2- Psicológicos-psiquiátricos}

El individuo inmerso la gran parte de su tiempo en las redes cibernéticas se acostumbra a un nivel de poca expresividad emocional al recurrir con frecuencia a comunicarse mediante mensajes de texto los cuales despojan de contenido y expresividad emocional sus contactos personales. Se pierde el componente de gesticulación facial y corporal que le da un sentido afectivo a la comunicación humana. Los artefactos tecnológicos se interponen como intermediarios obligados de los procesos de interacción y se convierte en un acto más frío y utilitario. En Japón, se 
Invest. pens. crit.

Vol. 2, No. 3, enero-abril 2014.

pp. $53-58$

da el llamado fenómeno "hikikomori" el cual ocurre en el adolescente que eligen vivir en un aislamiento social agudo y se confinan en sus hogares. El joven se vuelve letárgico, aislado, poco comunicativo. Tampoco comparte tiempo con sus familiares, no tiene relaciones románticas y comúnmente sufre de ansiedad, arranques de ira y a veces, depresión e insomnio. Está conectado casi todo el día a internet y no estudia ni trabaja. Este patrón conductual se ha observado y cada vez más frecuentemente en Europa y Estados Unidos. También se empieza a ver en las consultas de psicólogos y psiquiatras asociados en muchos casos a conductas adictivas, la llamada "tecnoadicción" la que a su vez puede ser a los videojuegos o la pornografía. Algunos paidopsiquiatras dan cuenta de que algunos de estos jóvenes son víctimas de acoso escolar (bullying) o de problemas de personalidad. Normalmente hay una falta de afecto parental y de controles y límites al uso del tiempo libre del joven con una actitud de indiferencia o negligencia. La falta de comunicación familiar es un factor común en los casos más extremos en los que se manifiestan cuadros de ansiedad y/o depresión. El insomnio y el consumo de sustancias psicotrópicas pueden verse en algunos de estos casos. Entre las señales que deben detectarse en un joven con este síndrome amotivacional por abuso de las tecnologías informáticas están: 1humor depresivo y colérico frecuente, 2- bajo rendimiento escolar, 3- desafiante con sus familiares y a la vez muy demandante; sobre todo con su madre.

Las manifestaciones descritas se enmarcan en un ambiente familiar de poca comunicación, padres separados y estilo parental indulgente o negligente con los hijos. Las tecnologías son una justificación y un escape a la vez de un estado vivencial de vacío y pérdida de sentido de la vida. Los padres hoy día promueven desde tempranas edades el consumismo en los hijos y de la "necesidad" de estar actualizando lo modelos de aparatos móviles y demás artefactos tecnológicos. Se crían los hijos para que sean felices y no para ser responsables consigo mismos y los demás. Se alienta el narcisismo y la conducta individualista. Los padres no cumplen con su rol de supervisores del hogar y desconocen en muchas ocasiones el uso que sus hijos hacen de internet.

Un aspecto de importancia en la utilización inadecuada de las tecnologías informáticas es que las mismas superan la capacidad de concentración y lleva a una conducta de multitareas (en inglés multitasking). El cerebro no puede hacerlo sin sobrecargarse de estrés. La constante distracción por revisar los aparatos móviles ha traído accidentes de autos, baja productividad laboral e indiferencia social. El bombardeo mediático intenso del tema sexual ha llevado al aumento de conductas de riesgo y a convertir la actividad sexual en una despojada de su sana áurea de discreción y sutil juego de seducciones. 
Invest. pens. crit.

Vol. 2, No. 3, enero-abril 2014.

pp. $53-58$

\section{3- Sociales-culturales}

La tecnologización de la vida social trae apuro, distractibilidad, superficialidad en muchos aspectos como la trivialización de la cultura y la ciencia. Se masifica el conocimiento y la información y todo adquiere carácter relativo, todo se cuestiona en parte debido a la divulgación de datos e informaciones inexactas (información basura).

Mario Vargas Llosa en un excelente ensayo define la situación imperante como el de "La civilización del espectáculo”. Esto, según el laureado escritor, producto de una cultura del entretenimiento en la que las tecnologías informáticas juegan un rol primordial con vídeos, música, textos y demás que hacen que estos artefactos sean utilizados como tecnologías de la diversión y no de la información y el conocimiento. Son las llamadas plataformas del entretenimiento. Se convierten en un "ecosistema de la distracción" (Carr, 2010). Los adolescentes y jóvenes adultos son los más propensos a verse envueltos en esta vorágine de banalizaciones y baja valoración del esfuerzo intelectual llevando a una cultura de lo efímero y superficial. El consumismo se impone y penetra en la vida privada de millones de personas. Hay una pérdida de los espacios privados los que son publicados en las redes sociales a cada momento disminuyendo los contactos interpersonales. El mundo virtual se traslapa con el mundo real y la espiritualidad es vacía. El hombre de la hipermodernidad vive agobiado de mensajes e información que lo llevan al estrés y a una cotidianidad superficial. Hay marcada indiferencia a la vida y a los espacios públicos. El ensimismamiento y soledad del ser humano se intensifican en estos tiempos. El valor diversión es un escape a la alienación del hombre y anula la priorización del trabajo y el esfuerzo intelectual porque todo se hace y se copia al instante. La impaciencia y la búsqueda hedonista en las pantallas trastocan las prioridades culturales y sociales del mundo de hoy. La literatura y el arte se publican como una mercancía; la ciencia se divulga como un producto de consumo; hay poco análisis y no se profundiza en los temas fundamentales de la sociedad. Una masa de ciudadanos inmersos en el entretenimiento tecnológico socava los cimientos de la civilización tal como se conoce hasta ahora.

\section{Conclusiones}

Es indudable que las tecnologías informáticas han llegado para quedarse en el mundo de hoy llamado "posmodermo" o "hipermoderno", según otros autores. La tecnologización de empresas y escuelas ha traído avances en cuanto a búsqueda de datos e información, diseños de plataformas computarizadas que han mejorado la productividad y la rapidez de procesos antes engorrosos. También se ha incrementado el tiempo de ocio para muchos mejorando la calidad de vida. La tecnología es un factor que ha impulsado la efectividad de las comunicaciones y las investigaciones académicas y ha permitido el diseño de estrategias de producción más amigables con el ambiente; así como la facilitación de la gestión administrativa en empresas y gobiernos. Otro efecto beneficioso de las computadoras e internet es la libertad de expresión en medios de comunicación y a nivel de grupos sociales e individuos, lo cual ha reducido la interferencia indebida de los sectores políticos. Las redes sociales son hoy en día un factor importante en la 
Invest. pens. crit.

Vol. 2, No. 3, enero-abril 2014.

pp. $53-58$

gestión de necesidades sociales y políticas con un potencial de expansión de la democracia liberal y de denuncia contra abusos.

No obstante, hay muchos riesgos y efectos colaterales negativos muy preocupantes que empañan sus ventajas. Entre estos podemos mencionar la invasión de la privacidad que en jóvenes inmaduros lleva a ponerse en riesgo respecto a propuestas de relación afectiva o sexual o a la inducción de grupos que promueven conductas delictivas o de consumismo enfermizo.

La persistente presión para responder interactivamente a los requerimientos de las tecnologías es un elemento distractor que influye en gran manera en el bajo desempeño escolar y laboral de quienes utilizan internet continuamente. La capacidad de análisis y memoria es mermada por el desbordamiento de datos e información a los que son presionados a responder los usuarios de las tecnologías de la información. Hay una actitud de encerramiento y falta de interés en las actividades sociales e intelectuales. La instantaneidad forma parte de los hábitos mentales de los jóvenes lo que no ayuda a madurar y a buscar el autocontrol en el uso de estos artefactos. Los usuarios frecuentes de computadores, móviles y demás aparatos computarizados con conexión están propensos a la tecnoadicción, un problema de salud mental muy contemporáneo. La sustitución paulatina de las funciones mentales humanas por las computadoras en búsqueda de la "inteligencia artificial" afecta los procesos de comunicación y trastoca lo que es la esencia de la naturaleza humana. La humanidad, a través de las instituciones de la familia y la educación, las organizaciones religiosas y políticas y la sociedad entera tienen un reto por delante de construir cultura y civilización integrando los avances de la tecnología y de que estos no conlleven a la enajenación psicológica y espiritual del ser humano.

\section{Bibliografía}

Carr, N. (2010). Superficiales: ¿Qué está haciendo internet con nuestras mentes? Bogotá: Taurus.

Arias, F. (28 de agosto de 2013). La inseparable memoria digital. La Prensa, suplemento Vivir + .

Prinz, U. y Rith-Magni, I. (Eds.). (2012). La educación: entre el corazón y la razón [Número especial]. Revista Humboldt, 55.

Golumbia, D. (2009). The cultural logic of computation. Massachussetts, EEUU: Harvard University Press.

Wexler, B. (2006). Brain and culture: Neurobiology, ideology, and social change. Massachussetts, EEUU: MIT Press. 